\title{
Fire Blight Resistance in Wild Accessions of Malus sieversii
}

\author{
Julia M. Harshman, Kate M. Evans, and Haley Allen, Department of Horticulture, Washington State University, Tree Fruit Research and \\ Extension Center, Wenatchee, WA 98801; Ryan Potts and Jade Flamenco, United States Department of Agriculture, Agricultural Research \\ Service, Appalachian Fruit Research Laboratory, Kearneysville, WV 25430; Herb S. Aldwinckle, Plant Pathology and Plant-Microbe Biology \\ Section (Emeritus), College of Agriculture and Life Sciences, New York State Agricultural Experiment Station, Cornell University, Geneva, \\ NY 14456; and Michael E. Wisniewski and John L. Norelli, ${ }^{\dagger}$ United States Department of Agriculture, Agricultural Research Service, \\ Appalachian Fruit Research Laboratory, Kearneysville, WV 25430
}

\begin{abstract}
Fire blight (Erwinia amylovora) is a devastating bacterial disease in apple that results in severe economic losses. Epidemics are becoming more common as susceptible cultivars and rootstocks are being planted, and control is becoming more difficult as antibiotic-resistant strains develop. Resistant germplasm currently being utilized by breeding programs tend to have small fruit size and poor flavor characteristics. Malus sieversii, a progenitor species of domestic apple, is notable for its relatively large, palatable fruit and some accessions have been reported to be resistant to fire blight. In this study, nearly 200 accessions of $M$. sieversii and

appropriate controls were inoculated with E. amylovora in both Washington and West Virginia to identify fire blight resistant accessions. Twelve accessions were identified with resistance comparable to highly resistant and resistant controls. Several accessions exhibited a unique resistance response, not previously reported in domestic apple $(M . \times$ domestica), characterized by low incidence of infection but high severity once infection was initiated. Several of these M. sieversii accessions will be used as parents in future crosses in the Washington State University apple breeding program.
\end{abstract}

Fire blight, caused by the bacterium Erwinia amylovora (Burrill) Winslow et al., is a devastating disease of apple (Malus $\times$ domestica Borkh.) that can kill young trees outright or result in permanent structural damage to mature trees. Fire blight remains a challenging disease to control, even with use of cultural practices to reduce primary inoculum and copper, biological, and/or antibiotic sprays to limit pathogen multiplication (van der Zwet et al. 2012). Streptomycin-resistant E. amylovora strains threaten the use of streptomycin as a management tool (McManus et al. 2002; McManus and Jones 1994; Russo et al. 2008) and the use of antibiotics by U.S. organic growers has been revoked (USDA, NOP 2015). Fire blight epidemics often develop explosively and the limited number of effective management practices available to growers makes it difficult to slow or stop the progress of these outbreaks. Most commercially successful apple cultivars introduced in recent decades, such as Braeburn, Fuji, Gala, Pink Lady (Cripps Pink), and even newly released cultivars such as RubyFrost (NY-2), are more susceptible to fire blight than older cultivars such as Delicious (Breth 2014; Brown 2012). Recent plantings of susceptible scion cultivars on susceptible rootstocks has further increased the potential of fire blight epidemics in apple orchards to unprecedented levels (Norelli et al. 2003a, b).

Host plant resistance is one of the most effective and sustainable options for managing fire blight; however, most resistant domesticated apple cultivars do not meet the horticultural and fruit quality standards required by the industry. Quantitative trait loci (QTL) associated with resistance have been identified in several Malus species that explain phenotypic variance ranging from 15 to $83 \%$ (Calenge

${ }^{\dagger}$ Corresponding author. E-mail: jay.norelli@ars.usda.gov

Mention of trade names or commercial products in this publication is solely for the purpose of providing specific information and does not imply recommendation or endorsement by Washington State University or the U.S. Department of Agriculture.

*The $\boldsymbol{e}$-Xtra logo stands for "electronic extra" and indicates that one supplementary table is published online.

Accepted for publication 15 June 2017.

This article is in the public domain and not copyrightable. It may be freely reprinted with customary crediting of the source. The American Phytopathological Society, 2017. et al. 2005; Durel et al. 2009; Emeriewen et al. 2014; Gardiner et al. 2012; Khan et al. 2007; Le Roux et al. 2010; Flachowsky et al. 2008). QTLs conferring the highest level of resistance are from wild species with undesirable fruit qualities, such as small size and bitter or astringent flavors. These sources are actively being used in rootstock breeding and several scion breeding programs in Europe that employ accelerated breeding strategies (Fazio et al. 2011; Flachowsky et al. 2011; Khan et al. 2012; Khanizadeh et al. 2000; Le Roux et al. 2012). The U.S. apple industry is dependent on growing high value scion cultivars prized for their fruit quality and the negative effects of wild species on fruit quality are time-consuming to overcome with conventional breeding methods.

$M$. sieversii (Lebed.) M. Roem. is one of the primary progenitor species of M. $\times$ domestica (Luby 2003). Native to central Asia, this species has long been of interest for increasing genetic and phenotypic diversity in domestic apple (Janick 1996; Volk et al. 2015). The USDA Agricultural Research Service's (ARS) National Plant Germplasm System (NPGS) sponsored four expeditions between 1989 and 1996 to collect $M$. sieversii in 12 climatically diverse sites located in Kazakhstan, Kyrgyzstan, Tajikistan, and Uzbekistan (Forsline et al. 2003; Table 1). These expeditions resulted in an extensive collection of 130,000 seeds from 892 trees that were subsequently distributed to research centers in the U.S. and other countries (Luby et al. 2000). Phenotypic evaluation, including postharvest disease performance, and resistance and tolerance to abiotic and biotic stresses of this material has been conducted in the U.S., Europe, and New Zealand (Fazio et al. 2011; Forsline and Aldwinckle 2004; Geibel et al. 2000; Janisiewicz et al. 2008; Jurick et al. 2011; Luby et al. 2002). Approximately 1,200 M. sieversii seedlings from 106 half-sibling families (i.e., seeds collected from the same mother tree) were planted in an orchard at the USDA-ARS-Plant Genetic Resources Research (PGRR) in Geneva, NY (Forsline et al. 2008). Some of the trees planted at USDA-ARS-PGRR, Geneva, NY, and the University of Minnesota (MN) have become permanent accessions described in the Germplasm Resources Information Network (GRIN; USDA-ARS-NPGS 2008).

Many of the $M$. sieversii seedling accessions have been evaluated for fire blight resistance using both natural occurrence in established field plantings and controlled inoculations in greenhouse trials of grafted material. Natural incidence of infection was recorded on 1,151 seedlings planted in 1997 and 1998 at USDA-ARS-PGRR Geneva, NY (Forsline and Aldwinckle 2002) and 1,410 accessions planted in 1998 in MN (Forsline et al. 2008). A total of 124 families were evaluated, with 32 
represented at both sites. Low incidence of fire blight susceptibility was recorded in 12 families, and a total of 535 accessions were rated as highly resistant or resistant (Fazio et al. 2009). In New Zealand, 936 seedlings from 52 families were evaluated for natural infection and only $13 \%$ showed signs of fire blight infection (Forsline et al. 2003; Luby et al. 2002). Accessions exhibiting susceptibility to natural occurrence of infection are also likely to be susceptible under controlled inoculation, while those that appear resistant may have escaped infection. The combination of high levels of fire blight resistance and large, palatable fruit make $M$. sieversii accessions excellent potential parental germplasm for breeding disease resistant scions (Forsline and Aldwinckle 2002; Forsline et al. 2008), as compared with other wild Malus species, which tend to have poorer fruit quality (Luby et al. 2000).

Richards et al. (2009b) characterized 949 M. sieversii accessions from eight collection sites for genetic diversity and population structure using seven microsatellite loci. Genetic diversity was significantly different between collection sites and the level of within-site variation also differed between sites, with variation among half-sib families having the largest effect on genetic structure. Intrasite genetic variation was greatest at sites 5,11 , and 12, whereas sites 4 and 9 showed the least diversity. When individual accessions were clustered by genotype, regardless of family or collection site, four genetic clusters were identified. Cluster 1 and 2 were common and found at all sites. Based on these data and phenotypic evaluation, a stratified core set of 112 accessions were selected that captured the majority of genetic and character trait variation (Richards et al. 2009a).

Plantings of $M$. sieversii that encompass most of the genetic diversity within species and include many accessions reported to be fire blight resistant were established in East Wenatchee, WA, and Kearneysville, WV. The goal of the present study was to obtain quantitative measures of fire blight resistance following controlled inoculation of a set of $M$. sieversii accessions. This information could then be used to identify genotypes for use in breeding efforts to incorporate fire blight resistance.

\section{Materials and Methods}

Plant material and orchard establishment. Based on previous phenotypic and genetic evaluation of $M$. sieversii accessions grown at the USDA-ARS-PGRR Geneva, NY, 194 M. sieversii accessions were selected for use in this study. Most of the available accessions from the stratified core sets previously described by Richards et al. (2009a), which represents the majority of phenotypic and genetic diversity of the collected $M$. sieversii germplasm, were initially selected (88 individuals included). Additional accessions were selected to obtain a 1:1 ratio of fire blight susceptible and resistant accessions based on the presence or absence of naturally occurring fire blight shoot infections on the $M$. sieversii accessions evaluated at the USDA-ARS-PGRR Geneva, NY. This was done to facilitate subsequent association mapping studies. Accessions with shoot infections were presumed to be susceptible to fire blight; however, the absence of shoot infections was due to either resistance or escape from infection. Previous research established that $40 \%$ of the accessions without natural fire blight infection were susceptible in controlled greenhouse inoculation tests (Forsline et al. 2008). Therefore, the number of presumed resistant accessions was increased accordingly, unless supporting data for resistance was available from previous greenhouse evaluations. In addition to resistance to fire blight, resistance to scab (Venturia inaequalis (Cooke) G. Winter 1875), resistance to cedar apple rust (Gymnosporangium juniperi-virginianae (Schwein. 1822), high fruit soluble solids content, fruit acidity (avoiding low and very high acidity), later fruit harvest dates, fruit weight, and fruit flavor (avoiding bitter, sour, and astringent flavors) were used as criteria in the selection of additional accessions.

Several controls with different resistance levels were included: highly resistant (M. × robusta 5$)$, resistant (Delicious), moderately resistant (Empire, Golden Delicious), and highly susceptible (Jonathan, Gala) (Aldwinckle and Preczewski 1976; Gardner et al. 1980; van der Zwet and Beer 1991). In addition, three modern cultivars reported to be resistant, GoldRush (Crosby et al. 1994), Fiesta (Khan et al. 2007), and Splendour (van der Zwet and Beer 1991) were included for comparison. All controls were scored in both years in West Virginia. In Washington, only three controls had sufficient growth to permit inoculation with E. amylovora: Golden Delicious and Jonathan (2013, 2014), and Splendour (2013).

Budwood of selected accessions and control cultivars was collected from the USDA-ARS-PGRR in Geneva, NY, and budded on M.7 rootstocks at Van Well Nursery, East Wenatchee, WA, in fall 2010. Sites in WA and WV were planted in spring of 2012. The Washington State University (WSU) Columbia View orchard in East Wenatchee, WA (WA) was planted in two sections, with 103 accessions in the first, 124 accessions in the second, and 21 duplicated in both sections. Each plot was planted as a randomized complete block design with three replications at $4.9 \mathrm{~m}$ between-row and $1 \mathrm{~m}$ in-row spacing. The orchard at USDA-ARS, Kearneysville, WV (WV) was planted in a randomized complete block design (1 rep per block) with four replications per accession at $6 \mathrm{~m}$ between-row and $2.1 \mathrm{~m}$ in-row spacing. Each site was planted with 197 of the same M. sieversii accessions and controls. There were unique accessions planted in WV (GMAL4054.z, GMAL4002.p, Fiesta) and WA (GMAL4209.g).

Inoculum and inoculation. Freeze-dried E. amylovora strain $153 \mathrm{n}$ was used for inoculation and prepared following methods outlined by Stockwell et al. (1998). The same freeze-dried 153n was used for inoculum preparation in both locations each year. Desired inoculum concentrations $\left(2 \times 10^{8} \mathrm{CFU} \mathrm{ml}^{-1}\right.$ in $2013,1 \times 10^{9} \mathrm{CFU} \mathrm{ml}^{-1}$ in 2014) were obtained by diluting with $0.01 \mathrm{M}$ dibasic phosphate buffer, $\mathrm{pH} 7$. Inoculum concentrations were verified by dilution plating.

Up to five shoots (2013) or 10 shoots (2014) per tree were selected for inoculation. Selected shoots were actively growing, had at least $10 \mathrm{~cm}$ of new growth, and were on independent branches from other selected shoots (Norelli et al. 2003a). Trees were inoculated by bisecting the shoot tip with scissors dipped in E. amylovora inoculum as described by Norelli et al. (1988). To determine the current season's shoot length at the time of inoculation, shoots were measured from the first bud scale scar to either the apical meristem (measured prior to inoculation, WA) or to the first cut leaf (measured postinoculation, WV). Trees were inoculated on 4 June at WV and 12 June at WA in 2013 and on 3 June at WV and 30 May at WA in 2014. The total length of necrotic fire blight lesions was recorded once disease

Table 1. Description of Central Asian collection sites for Malus sieversii (data from Forsline et al. 2003)

\begin{tabular}{|c|c|c|c|c|}
\hline Site $^{\mathbf{a}}$ & Area & Elevation (m) & Annual precipitation (mm) & Climate notes \\
\hline 1 & Tajikistan & NA & NA & NA \\
\hline 2 & Uzbekistan & NA & NA & NA \\
\hline $3 * / 8$ & Kazakhstan-Zailisky & $1,170-1,690$ & 700 & Humid temperate, mixed forest \\
\hline $4^{*}$ & Kazakhstan-Djungarsky & $1,170-1,760$ & 800 & Humid temperate, mixed forest \\
\hline $5^{*}$ & Kazakhstan-Djungarsky & $1,190-1,360$ & 850 & Humid temperate, mixed forest \\
\hline $6^{*}$ & Kazakhstan-Karatau & $600-910$ & 250 & Xeric, mixed scrub forest with diverse riparian habitat \\
\hline $7 *$ & Kyrgyzstan & $1,300-1,500$ & 1,300 & Very humid, temperate mixed forest \\
\hline $9 *$ & Kazakhstan-Tarbagatai & $870-1,120$ & 450 & Dry continental forest $\left(40^{\circ} \mathrm{C} \max /-40^{\circ} \mathrm{C} \mathrm{min}\right)$ \\
\hline $10^{*}$ & Kazakhstan-Ketmen & $1,600-1,700$ & 650 & Semidry, temperate mixed forest \\
\hline $11^{*}$ & Kazakhstan-Karatau & $780-1,230$ & 250 & Xeric mixed scrub forest with diverse riparian habitat \\
\hline $12 *$ & Kazakhstan-Talasky & $1,000-1,025$ & 320 & Dry canyon, mixed forest, N. slope of $300 \mathrm{~m}$ canyon \\
\hline
\end{tabular}

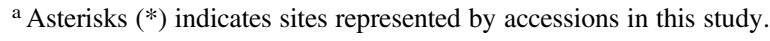


progression had stopped (4 to 6 weeks later). Lesions did not necessarily girdle the stem and length of noncontinuous lesions was the total sum of necrosis length. The age of the wood that the lesion extended into was recorded as $0=$ no infection, $1=$ current season's shoot growth, 2 = previous season's growth, etc. In addition, naturally occurring blossom and shoot infections that were not the result of controlled fire blight inoculation were recorded and monitored.

Statistical analysis. The measure of fire blight resistance in this study was the proportion of current season's shoot growth that was blighted following inoculation with E. amylovora 153 n (SLB). To satisfy the assumption that residual variation is normally distributed, SLB was logit transformed (LogitSLB). Prior to transformation, zero percentage data were randomly assigned a value between 0.001 and 0.0001 .

All analyses of variance were performed using the GLIMMIX procedure of SAS 9.4 (SAS Institute Inc., Cary, NC, U.S.A.). Initially, analysis of variance was performed on the complete dataset to test fixed effects of evaluation location (WA, WV), evaluation year (2013, 2014), and accessions on LogitSLB (data not shown). Interactions between years and locations due to composition of accessions evaluated in WA dictated separating analyses by location. For all analyses, interaction terms that were not significant were removed from the model. Block/plot within location, rep within location (WA), and row position within location were included as random effects. Mean separations were performed using the Tukey option at the $P<0.05$ level. The following analyses of variance were performed on accessions scored in WV: 1) to test the fixed effects of evaluation year and accessions on LogitSLB; 2) to test the fixed effects of evaluation year and genetic cluster on LogitSLB (genetic cluster of the accession was obtained from published results [Richards et al. 2009b]; and 3) to test the fixed effects of evaluation year and collection site on LogitSLB (collection site was obtained from the GRIN database [USDA-ARS-NPGS 2008]). One analysis of variance was performed on the 64 accessions scored in both WV and WA in both years to test fixed effects of evaluation location (WV, WA), evaluation year, and accessions on LogitSLB.

Of the accessions included in this study, 188 were previously evaluated for natural occurrence of infection in established field plantings (Forsline et al. 2003; USDA-ARS-NPGS, 2008) using a 1 to 5 scale (1: very resistant - no occurrence; 2 : moderately resistant - only light rating; 3: intermediate - light to medium rating; 4 : moderately susceptible medium to heavy rating; 5 : very susceptible - very heavy rating [Forsline and Aldwinckle 2002]). Accessions inoculated at WV were assigned resistance categories (HR, R, M, S, HS) to facilitate comparison with GRIN data. Rankings were first assigned based on controls that performed as expected to help define an approximate percent SLB boundaries for all five classes. Mean separation clusters that best represented boundaries for those classes were then chosen to complete the assignment.

Data from 17 greenhouse inoculations performed over six years (2004-2009) at USDA-ARS-PGRR Geneva, NY, was obtained for 121 accessions also inoculated in this field study $(\mathrm{H}$. Aldwinckle, personal communication). E. amylovora strain Ea273 was used to inoculate greenhouse-grown plants using the cut-leaf method (Volk et al. 2008). The proportion of the shoot blighted was similarly transformed to LogitSLB. An analysis of variance (Proc GLIMMIX) was performed with test date as a random effect and mean separations were performed using the Tukey option at the $P<0.05$ level. The number of shoots inoculated and LSMeans are presented in Supplementary Table S1. Using the REG procedure, a correlation analysis was performed for the 122 accessions scored in both the greenhouse study and this study. Three separate regressions were performed: a two-way analysis between greenhouse and WV 2013, a two-way analysis between greenhouse and WV 2014, and a three-way analysis between greenhouse, WV 2013, and WV 2014.

\section{Results}

Fire blight resistance of $M$. sieversii accessions planted in West Virginia. Diverse responses were observed among wild apple accessions after inoculating vigorously growing shoot tips with $E$. amylovora, ranging from highly susceptible to highly resistant. $M$. sieversii accessions exhibited greater variability in their susceptibility to fire blight than $M . \times$ domestica controls. Typical fire blight infections developed on many of the accessions. Interaction between accession and year was significant $(P<0.001)$ in WV. Therefore, the analysis was split by year and effect of accession on logit transformed proportion shoot length blight (LogitSLB) was significant for both $2013(P<0.001)$ and $2014(P<0.001)$. Three accessions were significantly $(P=0.05)$ more susceptible to fire blight than $\mathrm{cv}$. Jonathan in 2013 and 25 accessions were significantly more susceptible than cv. Gala in 2014. Eleven of the 19 Jonathan shoots inoculated in 2013 developed large lesions, resulting in death of one replicate and reliance on Gala as the susceptible control in 2014.

None of the $M$. sieversii accessions were significantly more resistant than $M . \times$ robusta 5 or Delicious due to the slight amount of fire blight shoot infection on the resistant controls; however, 41 (2013) and 98 (2014) accessions had lower SLB values (i.e., were more resistant) than Delicious. Fire blight resistance of GMAL3608.h, GMAL4002.k, PI657115, and PI657116 was equivalent to the highly resistant control $M . \times$ robusta 5 in more than one test. GMAL3616.o, GMAL4002.m, GMAL4028.h, GMAL4211.d, PI657054, and PI657085 had slight fire blight development in one test, but also appeared comparable to $M . \times$ robusta 5 in resistance. GMAL3544.b, GMAL3688.c, GMAL3975.c, GMAL3989.c, GMAL4059.a, GMAL4211.a, GMAL4211.e, GAML4211. $\mathrm{g}$, and PI657044 developed fire blight comparable to Delicious, a resistant control cultivar.

Multiple accessions appeared to be resistant in one year and susceptible in the other (Fig. 1). For example, PI633921 showed good resistance in 2013 with only two of 20 inoculated shoots developing a lesion, and both were 0.1 SLB $(4 \mathrm{~cm})$. In contrast, 29 of 32 shoots developed infections in 2014, 11 of which progressed into second year wood and one into third year wood. GMAL4032.i had a similar response: only one of 20 shoots inoculated in 2013 developed a lesion (0.14 SLB), while 15 out of 36 inoculated shoots developed lesions in 2014, eight of which progressed into second year wood, and three of which progressed into third year wood.

Unique responses to $\boldsymbol{E}$. amylovora. In contrast to, and atypical from observations in domesticated apple cultivars (Aldwinckle and Preczewski 1976), several M. sieversii accessions appeared resistant to initiation of fire blight infection resulting in low incidence, but developed severe infections when an infection was successfully initiated, and those infections progressed into older wood in a single growing season. In the case of GMAL4028.h, infection was initiated in only one of 35 shoots inoculated in 2013 and 2014 but that infection progressed through second year wood into the central leader, resulting in tree death. The accession's average SLB and age of wood infected was still quite low. GMAL4055.w had a similar response. Only two of 25 inoculated shoots developed infection, but in both cases infections progressed into second and third year wood. Neither accession was inoculated in WA.

Fire blight resistance of standard apple varieties. Fiesta, Splendour, and GoldRush all sustained low levels of infection but were not significantly different from the controls $M . \times$ robusta 5 and Delicious. Eleven shoots of Fiesta were inoculated in 2014 in WV and two developed lesions, 0.025 SLB and 0.064 SLB, respectively. Thirty-three shoots of Splendour were inoculated in 2014 in WV and eight developed lesions, averaging 0.06 SLB among shoots with disease incidence. Twenty shoots of GoldRush were evaluated in 2013 in WV and only one of them developed a lesion, measuring 0.05 SLB.

Fire blight resistance in some accessions differed between $W V$ and WA. The WA planting sustained heavy deer browsing damage in spring and early summer of 2013, which had a lasting, detrimental effect on the planting. Therefore, not all accessions were evaluated in every test. Only 79 accessions in 2013 and 83 in 2014 had enough shoots with sufficient growth to be able to conduct reliable fire blight evaluations.

For the 64 accessions scored in both locations and years, interaction between accession, year, and location was significant $(P<0.0001)$. Separated by year, interaction between accession and location was 
significant for both 2013 and $2014(P<0.001)$. Standard error was larger in both years in WA than it was in WV (Fig. 2). In general, accessions performed similarly across the four trials with a few notable exceptions. PI633921 was fairly resistant in every trial except WV in 2014 where the average was $0.87 \mathrm{SLB}$. Several accessions, such as GMAL4047.o, GMAL4047.k, GMAL4039.y, and Jonathan, developed less disease in WA than they did in both years in WV. In 2013, PI657068, GMAL6383.e, and PI657097 were more susceptible in WA than in WV; however, no accessions were consistently more susceptible in WA in both years.

Controlled inoculations in WV were comparable to natural infections in NY. A total of 188 of the accessions inoculated in the present study were previously evaluated for susceptibility to natural infection in established field plantings at USDA-ARS-PGRR Geneva, NY. There was general agreement between the two tests for most accessions, with 94 accessions in 2013 and 99 in 2014 placed in similar

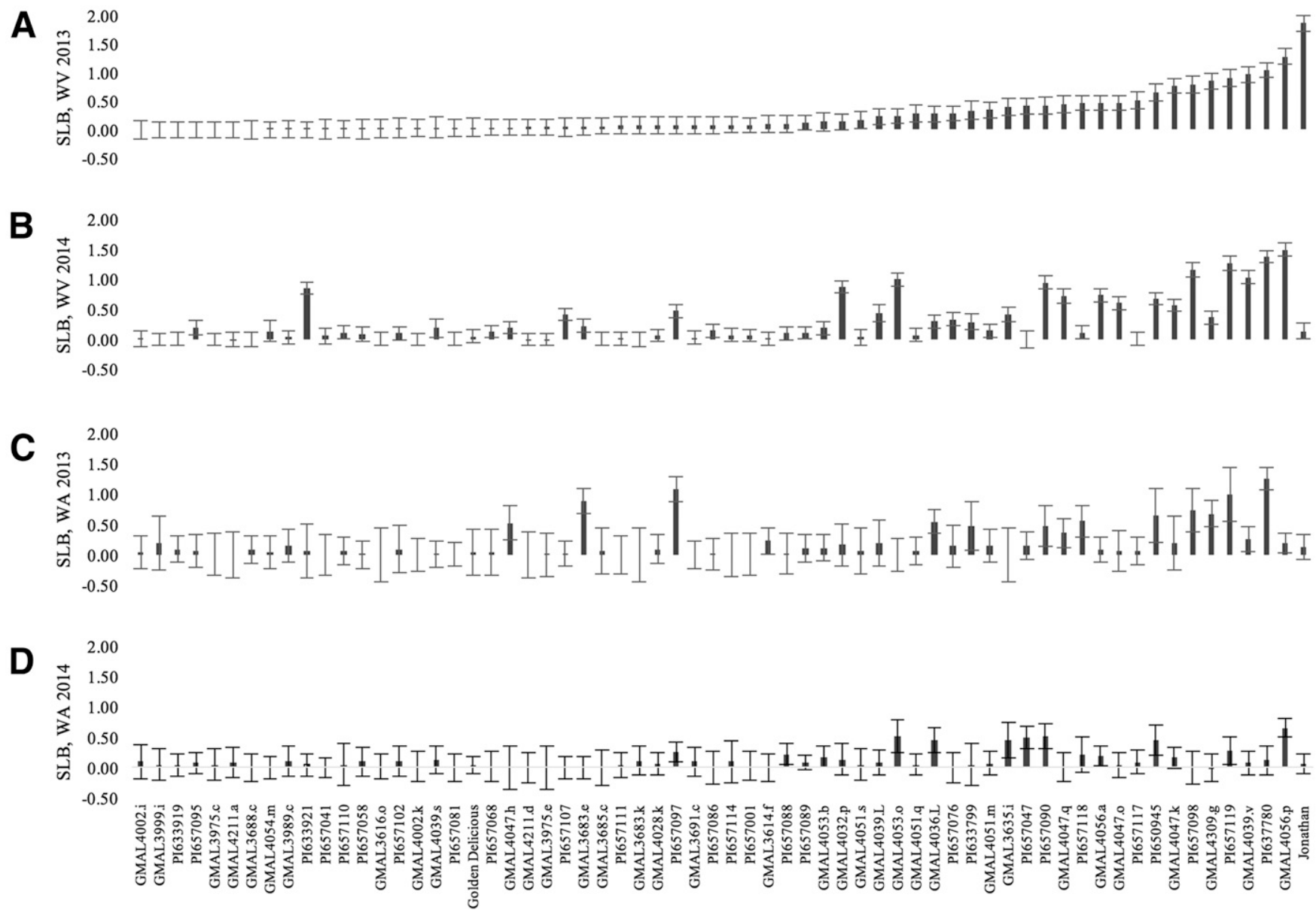

Fig. 1. Result of Erwinia amylovora shoot inoculation test for 64 Malus sieversii accessions and M. $\times$ domestica controls evaluated in both years and locations: A, 2013 at Kearneysville, WV; B, 2014 at Kearneysville, WV; C, 2013 at Wenatchee, WA; D, 2014 at Wenatchee, WA. Fire blight infection measured as SLB, the proportion of current season's shoot growth that was blighted following inoculation with $E$. amylovora.

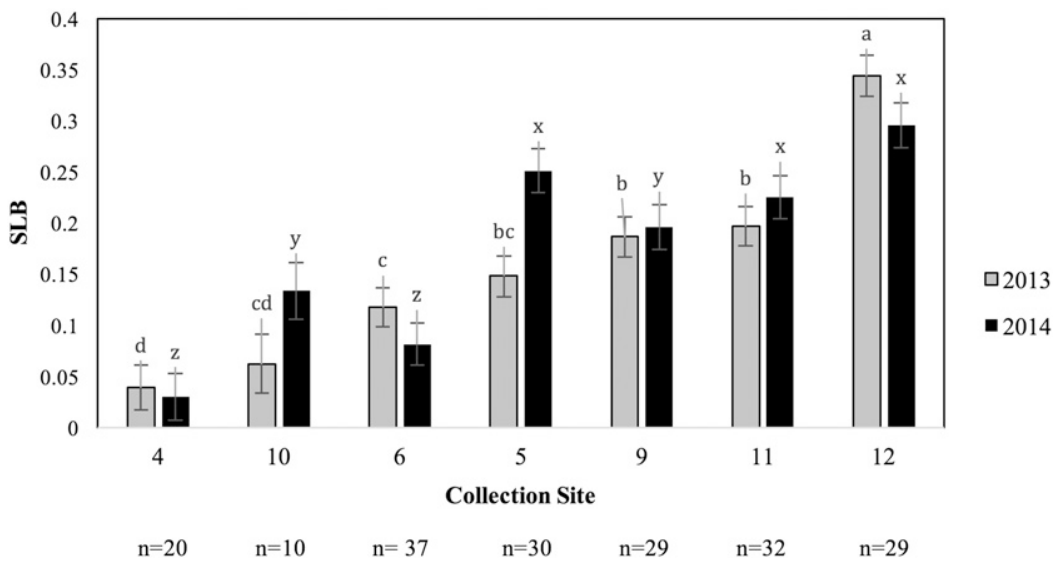

Fig. 2. Average fire blight infection for Malus sieversii accessions inoculated with Erwinia amylovora in Kearneysville, WV in 2013 and 2014 separated by their collection site. Fire blight infection measured as SLB, the proportion of current season's shoot length blighted after inoculation. The number of accessions collected from each site is listed below the site number. 
resistance categories (i.e., HR or R when inoculated and very to moderately resistant to natural infection). Those accessions deemed very to moderately resistant to natural infection that were rated as susceptible or highly susceptible in the inoculation studies likely escaped infection in the field. Nine accessions in 2013 and 11 in 2014 rated as moderately to severely susceptible based on natural occurrence of infection, however, were HR or R after inoculation.

Low correlation between controlled inoculations in $\mathrm{WV}$ and controlled inoculation in NY. A total of 121 accessions were evaluated in both the present study and in greenhouse tests conducted at the USDA-ARS-PGRR Geneva, NY. In the greenhouse test, accession had a significant effect on LogitSLB $(P<0.0001)$. Mean separations were informative for designating only highly resistant and highly susceptible accessions; however, those exhibiting intermediate levels resistance could not be parsed into resistant, moderately susceptible, or susceptible classes. Correlation between the leastsquare means for SLB in the greenhouse test and the $2013 \mathrm{WV}$ field was significant $(P<0.0001)$, but had a relatively low $\mathrm{R}^{2}$ of 0.1881 . The correlation between the greenhouse test and the $2014 \mathrm{WV}$ field test was not significant $(P=0.6946)$ and also had a very low $\mathrm{R}^{2}$ of 0.0013. When both 2013 and 2014 were included in the model, it was significant $(P<0.001)$ and the $\mathrm{R}^{2}$ value was slightly higher (0.1979) than with just 2013 WV data. Despite the low correlation, the majority of accessions inoculated had similar levels of resistance in both tests.

Collection site and genetic cluster were associated fire blight resistance of accessions. Every collection site had sufficient accessions to include in the analysis except site 3 (three accessions) and site 7 (two accessions). There was a significant interaction $(P<$ 0.0001 ) between collection site and evaluation year at WV, and therefore analysis was split by year. Fire blight resistance was significantly affected by collection site in both $2013(P<0.0001)$ and 2014 $(P<0.0001)$. Accessions collected from sites 4,10 , and 6 had lower SLB values than sites 11 and 12 in both 2013 and 2014 (Fig. 2). Accessions collected from site 12 had the highest SLB in both years. Site 12 was significantly different from the other sites in 2013 (Fig. 2). In 2014, accessions from site 12 remained the most susceptible, but were not significantly different from those collected from sites 11 and 5. Accessions from sites 4 and 10 had the lowest fire blight infection in 2013. In 2014, accessions from sites 4 and 6 had the lowest fire blight infection.

Genetic cluster data were available for 185 of the selected accessions. Interaction between genetic cluster and evaluation year was significant $(P<0.0001)$ in the data from $\mathrm{WV}$, so the analysis was split by year. Fire blight resistance was significantly affected by the genetic cluster of an accession in both 2013 and $2014(P<$ $0.0001)$. Accessions placed within genetic clusters 1 and 2 had significantly less fire blight than those within genetic cluster 3 in both years (Fig. 3). Accessions in genetic cluster 4 behaved differently in 2013 and 2014. These accessions were not significantly different from those in cluster 3 in 2013, yet appeared more resistant in 2014 and not significantly different from accessions in genetic clusters 1 and 2 . None of the other three clusters grouped with cluster 3 .

\section{Discussion}

Successful fire blight management is dependent on the severity of the disease; high incidence with low severity of individual fire blight infections can be managed effectively while infections that result in severe damage are harder to manage and the primary source of major economic losses (Norelli et al. 2003a, b). For this reason, shoot blight severity was chosen as the measure of resistance, rather than blossom blight incidence, as shoot blight typically leads to structural damage and economic losses. Blighted shoots result in economic losses from yield as they are typically pruned out. Shoot blight can also lead to severe structural damage or tree death, compounding economic losses over time.

A high concentration of the fire blight pathogen was used in evaluating resistance in these apple accessions to increase the chance that an infection would be initiated, and then resistance was evaluated based upon disease progression in the infected shoot. Inoculum concentration was one order of magnitude lower in 2013 to prevent destruction of young trees in the first year of the study. The proportion of current season's growth blighted is a standardized measure of fire blight infection and advantageous due to the phenotypic diversity of the material inoculated (Nybom et al. 2012; Peil et al. 2011; Sobiczewski et al. 2015). WV was chosen as the focus of analysis and results presented since all nine controls were evaluated and overall tree health and vigor were substantially better than the planting in WA.

In general, there was a high level of agreement between this series of controlled inoculations and published reports of natural occurrence of fire blight on $M$. sieversii accessions (Forsline et al. 2008). However, a total of 14 accessions were rated as resistant after inoculation but susceptible based on natural occurrence of infection. There are several possible explanations for this discrepancy. While evaluations based on blossom blight and shoot blight are generally in agreement, they are not $100 \%$ correlated (van der Zwet et al. 2012). Therefore, the number of accessions rated as more susceptible could have been higher in natural occurrence ratings based on blossom blight. Furthermore, susceptibility to fire blight is highly dependent on host vigor, and some genotypes may have appeared to be resistant when they were inoculated before or after the host was receptive. This could also account for the variability observed between growing seasons (Fig. 2). Similar discrepancies have been reported in studies reporting natural occurrence of infection (Forsline et al. 2008; Luby et al. 2002) and between natural occurrence and inoculation (Momol et al. 1999; Luby et al. 2002); however, those discrepancies were between different genotypes collected from the same mother tree. The discrepancies listed above are for the same genotypes.

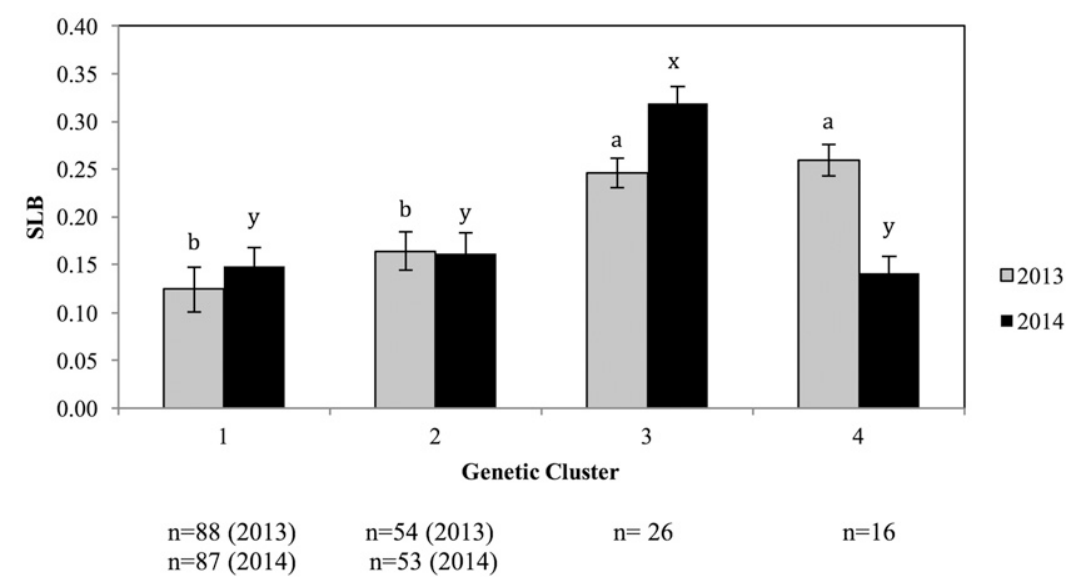

Fig. 3. Average fire blight infection for Malus sieversii accessions inoculated with Erwinia amylovora in Kearneysville, WV in 2013 and 2014 separated by genetic cluster. Fire blight infection measured as SLB, proportion of current season's shoot length blighted after inoculation. The number of accessions in each genetic cluster is listed below the site number. 
There was a low correlation between the previously conducted greenhouse inoculation evaluations done in NY and the current field inoculation test. This could be due to the use of two different strains (Ea273 vs. 153n), environmental differences between the greenhouse and field, the small number of shoots inoculated per accession in each greenhouse study (average of 3.3 replications per accession), or a combination of the three. Despite the low correlation, most accessions responded similarly.

For the most part, incidence (the number of infections per plant) of fire blight and severity (the relative size and effect of the infection) are well correlated in $M . \times$ domestica (Aldwinckle and Norelli 1981). In contrast, high severity with low incidence was observed in several accessions of $M$. sieversii. This atypical response suggests there are distinct host mechanisms for preventing infection by E. amylovora and for allowing the pathogen to spread once infection has been initiated. This type of resistance, low incidence but high severity, is less useful for breeding by itself as it would result in economic losses under severe infection. However, it could be useful in addition to other mechanisms of resistance to fire blight as it would lead to reduced frequency of infections and thus reduced inoculum load.

Fiesta, Splendour, and GoldRush are recently developed cultivars widely reported as resistant to fire blight (Crosby et al. 1994; van der Zwet and Beer 1991); however, field performance and controlled inoculation studies are scarce. In the current study, the resistance of Splendour and GoldRush was found to be similar to that of Delicious. The resistance of Fiesta, which has been used in QTL studies to map resistance (Khan et al. 2007), appeared slightly more resistant than Delicious.

Results from the present study indicate that accessions from collection sites 4, 6, and 10 were more resistant than those from sites 9,11 , and 12. Accessions from site 9 were among the most susceptible and accessions from site 6 exhibited a level of resistance similar to the most resistant site. Similarly, evaluation of natural infection in field grown seedling at $\mathrm{NY}$ and $\mathrm{MN}$ found that seedlings from site 6 were more resistant than those from site 9 (Forsline et al. 2008).
Seedlings from sites 1, 4, 5, and 6 also had lower disease severity in greenhouse studies with controlled inoculation (Momol et al. 1999). In contrast, evaluations of natural infection in New Zealand did not reveal any significant differences between the different sites (Luby et al. 2000).

There have been no published comparisons between genetic cluster and fire blight resistance to date. Accessions in genetic clusters 1 and 2 had the highest level of fire blight resistance. Genetic cluster 1 and 2 were the most common and found at all sites. Genetic clusters 3 and 4 were less represented than cluster 1 and 2, and therefore the analysis may be biased.

Fire blight severity is strongly influenced by environment, so it is necessary to evaluate resistance in multiple tests conducted under different environmental conditions to reliably separate the effect of the host's genetic resistance from effect of environment, thus accounting for genotype $\times$ environment interactions. M. sieversii accessions in the present study were effectively evaluated under four different environmental conditions by inoculating them in two different years in two planting locations (Wenatchee, WA, and Kearneysville, WV) that vary considerably in their climate. In many cases, an accession may have appeared highly resistant in some of the tests, but susceptible in others. This could be the result of resistance that is strongly influenced by environment and thus less useful in a breeding program. Although approximately 10 to $30 \%$ of trees appeared highly resistant in any individual test, only 6\% (12 accessions) were consistently highly resistant in multiple tests.

The efficacy of inoculation is also strongly influenced by host vigor. Ideally, accessions should be actively growing with at least $10 \mathrm{~cm}$ of growth at the time of inoculation. While growth stage of the $M . \times$ domestica cultivars was readily determined, growth stage of the $M$. sieversii material was far more challenging to determine. Multiple accessions had atypical growth forms and grew very little each year. Trees in WA that were compromised by deer browsing showed generally low plant vigor and growth stage was particularly difficult to determine. This may partially explain the discrepancy in disease severity observed between WA and WV. It is likely that some

Table 2. Results of Erwinia amylovora shoot inoculation test for resistant accessions and controls evaluated in both 2013 and 2014 and in both Kearneysville, $\mathrm{WV}$, and Wenatchee, WA, as well as available phenotypic information for commercially important traits

\begin{tabular}{|c|c|c|c|c|c|c|c|c|c|c|c|c|}
\hline \multirow[b]{2}{*}{ Accession } & \multicolumn{2}{|c|}{ WV 2013} & \multicolumn{2}{|c|}{ WV 2014} & \multicolumn{2}{|c|}{ WA 2013} & \multicolumn{2}{|c|}{ WA 2014} & \multirow[b]{2}{*}{ Tree $\operatorname{arch}^{\mathbf{b}}$} & \multirow[b]{2}{*}{$\mathrm{SSC}^{\mathrm{c}}$} & \multirow[b]{2}{*}{ Weight $^{d}$} & \multirow[b]{2}{*}{ Harvest season ${ }^{e}$} \\
\hline & $\overline{\mathbf{N}}$ & $\overline{\% \text { SLBa }^{a}}$ & $\mathbf{N}$ & $\overline{\% \text { SLB }}$ & $\overline{\mathbf{N}}$ & $\overline{\% \text { SLB }}$ & $\overline{\mathbf{N}}$ & $\overline{\% \text { SLB }}$ & & & & \\
\hline Malus $\times$ robusta 5 & 20 & 0.00 & 27 & 0.00 & & & & & 6 & & & \\
\hline GMAL3616.o & 15 & 0.00 & 31 & 0.20 & & & 4 & 0.00 & 1 & 11.1 & $<50 \mathrm{~g}$ & 50-60 days before Delicious \\
\hline GMAL3688.c & 19 & 0.60 & 38 & 3.30 & & & 4 & 0.00 & 13 & 12 & $<50 \mathrm{~g}$ & 20-30 days before Delicious \\
\hline GMAL3975.c & 20 & 0.3 & 38 & 2.00 & & & 4 & 0.00 & 6 & 13.5 & $<50 \mathrm{~g}$ & 10 days before Delicious \\
\hline GMAL3999.i & 19 & 0.00 & 38 & 0.00 & & & 3 & 0.01 & 1 & 13.4 & $<50 \mathrm{~g}$ & 20-30 days before Delicious \\
\hline GMAL4002.k & 20 & 0.00 & 40 & 0.00 & & & 4 & 0.00 & 2 & 11.1 & $<50 \mathrm{~g}$ & Delicious season \\
\hline GMAL4002.m & 20 & 0.00 & 38 & 0.30 & & & & & 6 & 13.9 & $50-100 \mathrm{~g}$ & 30-50 days before Delicious \\
\hline GMAL4028.h & 15 & 0.00 & 15 & 0.01 & & & & & 1 & NA & NA & NA \\
\hline GMAL4211.a & 20 & 0.00 & 28 & 0.90 & & & & & 11 & NA & NA & 30-50 days before Delicious \\
\hline GMAL4211.d & 20 & 0.70 & 39 & 0.00 & & & 5 & 0.00 & 5 & NA & NA & $>60$ days before Delicious \\
\hline GMAL4211.e & 20 & 0.00 & 35 & 0.02 & & & & & 6 & NA & NA & NA \\
\hline PI633919 & 20 & 0.00 & 38 & 0.00 & 5 & 0.08 & 8 & 0.04 & 2 & 10.2 & $50-100 \mathrm{~g}$ & 10 days before Delicious \\
\hline PI656998 & 19 & 0.02 & 14 & 0.01 & 3 & 0.01 & & & 13 & 11.3 & $<50 \mathrm{~g}$ & 50-60 days before Delicious \\
\hline PI657044 & 20 & 0.00 & 36 & 0.01 & & & & & 1 & 11.1 & $<50 \mathrm{~g}$ & 30-50 days before Delicious \\
\hline PI657054 & 20 & 0.00 & 40 & 0.40 & & & & & 1 & 12.7 & $50-100 \mathrm{~g}$ & Delicious season \\
\hline PI657085 & 19 & 0.00 & 37 & 0.50 & & & & & 7 & NA & NA & 30-50 days before Delicious \\
\hline PI657115 & 20 & 0.00 & & & & & 4 & 0.00 & 11 & 14.4 & $<50 \mathrm{~g}$ & 30-50 days before Delicious \\
\hline PI657116 & 15 & 0.00 & 15 & 0.00 & & & 4 & 0.10 & 6 & 14.2 & $<50 \mathrm{~g}$ & 30-50 days before Delicious \\
\hline Delicious & 18 & 1.10 & 38 & 3.80 & & & & & 7 & & & \\
\hline Golden Delicious & & & & & & & 17 & 5.60 & 13 & & & \\
\hline Gala & & & 31 & 24.50 & & & & & 13 & & & \\
\hline Jonathan & 19 & 74.00 & & & & & & & 14 & & & \\
\hline
\end{tabular}

a $\%$ SLB is the percent of current season's shoot growth that was blighted following inoculation with E. amylovora $153 \mathrm{n}$.

b Tree architecture descriptors as illustrated by Lauri and Laurens (2005).

c Soluble solids content as phenotyped by USDA-ARS-PGRR in Geneva, NY (USDA-ARS-NPGS 2008).

${ }^{\mathrm{d}}$ Average fruit weight as phenotyped by USDA-ARS-PGRR in Geneva, NY (USDA-ARS-NPGS 2008).

${ }^{\mathrm{e}}$ Harvest season as phenotyped by USDA-ARS-PGRR in Geneva, NY (USDA-ARS-NPGS 2008). 
were inoculated either before or after the "active" growth stage given the wide diversity of the accessions screened in this test.

Environmental conditions also influence inoculation efficacy. In WA, conditions were suboptimal during inoculation. Infection of E. amylovora occurs most readily between 21 and $27^{\circ} \mathrm{C}$, but can occur between 18.5 and 32 to $35^{\circ} \mathrm{C}$. Rain or periods of high humidity have long been associated with fire blight infection, with $80 \%$ relative humidity (RH) as the optimum (van der Zwet et al. 2012). Lower limits of RH sufficient for infection have not been reported, but blight has been induced at RH as low as 50\% (van der Zwet et al. 2012). Average temperature and humidity in WA during inoculation were $17^{\circ} \mathrm{C} / 43 \% \mathrm{RH}$ in 2013 and $20^{\circ} \mathrm{C} / 44 \% \mathrm{RH}$ in 2014 . There was no precipitation preceding or after inoculation either year. Temperatures were below optimum but within the range for fire blight infection, but lower than optimum RH may have hindered fire blight infection in WA. Conversely, average temperature and humidity in WV during inoculation were $18.7^{\circ} \mathrm{C} / 53 \% \mathrm{RH}$ in 2013 and $23^{\circ} \mathrm{C} / 68 \% \mathrm{RH}$ in 2014. In the three days following inoculation, there was $35.5 \mathrm{~mm}$ of rain in 2013 and $25 \mathrm{~mm}$ of rain in 2014.

Multiple accessions were identified with resistance that was stable over multiple tests and equal to or better than Delicious (Table 2). Of those 18 accessions, those scored as susceptible based on natural occurrence in the field (GMAL4059.a, GMAL4211.a, GMAL4211.e, and GMAL4211.g) or those with an SLB greater than $25 \%$ in the greenhouse inoculations (GMAL3544.b, GMAL4211.d, GMAL4211. g) are probably neither truly resistant nor suitable for use in breeding efforts. GMAL4028.h showed unique susceptibility, with low incidence and high severity, and is also likely not a good source of resistance to pursue for breeding. Slight natural infection was observed in PI657085. Other accessions were all rated as 1 or 2, and are likely resistant to fire blight. GMAL4059.a and GMAL4211.e highlight the importance of repeated resistance testing of accessions as they were resistant in both field and greenhouse inoculation tests, but susceptible to natural infection in the field.

The challenge remains that fruit size and quality of $M$. sieversii accessions are still far below industry standards; however, fewer introgression generations are anticipated when compared with sources with fewer domestic traits (e.g., $M . \times$ robusta 5 ), especially if the resistance is introduced into a background that already has some level of resistance, such as Splendour or Delicious. A long-term objective for use of these accessions is to pyramid multiple resistance genes to create high quality, commercially competitive apple varieties with durable and sustainable resistance to fire blight. Durable resistance is paramount as plantings last 20+ years. Identification of fire blight resistant sources with larger fruit and no unpleasant flavors will be critical to allow rapid progress in combining superior fruit quality and fire blight resistance. Data available for fire blight susceptibility of $M$. sieversii accessions has typically been qualitative and based on incidence. Precise quantitative data, as provided by this study, on severity as well as incidence is required for mapping studies. Genotype by sequencing (GBS) data has been obtained for these individuals with the goal of identifying specific resistance genes or QTLs. Existence of this genetic data will allow for the development of DNA tests for those genes or QTLs to augment breeding efforts to incorporate and pyramid resistance. Rapid methods of breeding, employing transgenic trees that exhibit precocious and constant flowering, can further accelerate introgression efforts. Use of these methods has been successfully demonstrated with other sources of fire blight resistance (Flachowsky et al. 2011; Le Roux et al. 2014).

In summary, this project has identified several excellent sources of fire blight resistance for use in apple scion breeding programs. Broadening the diversity of resistance sources available, especially those with different mechanisms of resistance, will enable the strategic development of durable multigene resistance to fire blight.

\section{Acknowledgments}

The authors thank Wilbur Hershburger and Roger Lewis of USDA-ARS, Kearneysville, WV, and Bonnie Schonberg, Lisa Brutcher, and Nancy Buchanan of the WSU-TFREC for their expert technical assistance in the project. They thank Gayle Volk of USDA-ARS, Plant Germplasm Preservation Research Unit, Fort Collins,
CO, and Phillip Forsline (retired), C. Thomas Chao, and staff of USDA-ARS, Plant Genetic Resources Research, Geneva, NY, for providing data on the collection and initial characterization of Malus sieversii accessions, as well as supplying budwood of accessions for plant propagation. They also thank the farm crews at USDA-ARS Kearneysville, WV, and WSU Columbia View Orchard for orchard maintenance.

This project was partially funded by the Washington Tree Fruit Research Commission ProjectsCP-10-110 and CP-12-104, and USDA-AFRI-NIFA Pre-doctoral Fellowship 123154-001 awarded to J. Harshman.

\section{Literature Cited}

Aldwinckle, H. S., and Norelli, J. L. 1981. Varietal differences in incidence of infection of apple blossoms and shoots by Erwinia amylovora (fire blight). Acta Hortic. 117:71-72.

Aldwinckle, H. S., and Preczewski, J. L. 1976. Reaction of terminal shoots of apple cultivars to invasion by Erwinia amylovora. Phytopathology 66:1439-1444.

Breth, D. 2014. Managing Fire Blight in Young RubyFrost Plantings. Empire State Producers Expo Proceedings. Online Publication. http://www.hort.cornell.edu/ expo/proceedings/2014/Tree\%20Fruit/Fire\%20Blight $\% 20$ in $\% 20$ Ruby $\% 20$ Frost $\%$ 20Breth.pdf

Brown, S. 2012. Apple. Pages 329-367 in: Fruit Breeding. M. L. Badenes and D. H. Byrne, eds. Springer Science \& Business Media, New York.

Calenge, F., Drouet, D., Denancé, C., Van de Weg, W. E., Brisset, M.-N., Paulin, J.-P., and Durel, C.-E. 2005. Identification of a major QTL together with several minor additive or epistatic QTLs for resistance to fire blight in apple in two related progenies. Theor. Appl. Genet. 111:128-135.

Crosby, J. A., Janick, J., Pecknold, P. C., Goffreda, J. C., and Korban, S. S. 1994 'Gold Rush' Apple. HortScience 29:827-828.

Durel, C.-E., Denancé, C., and Brisset, M.-N. 2009. Two distinct major QTL for resistance to fire blight co-localize on linkage group 12 in apple genotypes 'Evereste' and Malus floribunda clone 821. Genome 52:139-147.

Emeriewen, O., Malnoy, M., Richter, K., Kilian, A., Hanke, M.-V., and Peil, A. 2014. Evidence of a major QTL for fire blight resistance in the apple wild species Malus fusca. Acta Hortic. 1056:289-293.

Fazio, G., Aldwinckle, H. S., Robinson, T. L., and Wan, Y. 2011. Implementation of molecular marker technologies in the apple rootstock breeding program in Geneva-challenges and successes. Acta Hortic. 903:61-68.

Fazio, G., Aldwinckle, H. S., Volk, G. M., Richards, C. M., Janisiewicz, W. J., and Forsline, P. L. 2009. Progress in evaluating Malus sieversii for disease resistance and horticultural traits. Acta Hortic. 814:59-66.

Flachowsky, H., Le Roux, P. M., Peil, A., Patocchi, A., Richter, K., and Hanke, M. V. 2011. Application of a high-speed breeding technology to apple (Malus $\times$ domestica) based on transgenic early flowering plants and marker-assisted selection. New Phytol. 192:364-377.

Flachowsky, H., Richter, K., Garcia-Libreros, T., Celton, J.-M., Gardiner, S., Horner, M., Peil, A., Hanke, M.-V., and Bus, V. 2008. Confirmation of the fire blight QTL of Malus $\times$ robusta 5 on Linkage Group 3. Acta Hort. 793: 297-303.

Forsline, P. L., and Aldwinckle, H. S. 2002. Natural occurrence of fire blight in USDA Apple Germplasm Collection after 10 years of observation. Acta Hortic. 590:351-357.

Forsline, P. L., and Aldwinckle, H. S. 2004. Evaluation of Malus sieversii seedlings populations for disease resistance and horticultural traits. Acta Hortic. 663:529-534

Forsline, P. L., Aldwinckle, H. S., Dickson, E. E., Luby, J. J., and Hokanson, S. C. 2003. Collection, maintenance, characterization, and utilization of wild apples of Central Asia. Hortic. Rev. (Am. Soc. Hortic. Sci.) 29:1-62.

Forsline, P. L., Aldwinckle, H. S., and Luby, J. J. 2008. Fire blight incidence on Malus sieversii grown in New York and Minnesota. Acta Hortic. 793:345-350.

Gardiner, S. E., Norelli, J. L., de Silva, N., Fazio, G., Peil, A., Malnoy, M., Horner, M., Bowatte, D., Carlisle, C., Wiedow, C., Wan, Y., Bassett, C. L., Baldo, A. M., Celton, J., Richter, K., Aldwinckle, H. S., and Bus, V. 2012. Putative resistance gene markers associated with quantitative trait loci for fire blight resistance in Malus 'Robusta 5' accessions. BMC Genet. 13:25.

Gardner, R. G., Cummins, J. N., and Aldwinckle, H. S. 1980. Fire blight resistance in the Geneva apple rootstock breeding program. J. Am. Soc. Hortic. Sci. 105 907-912.

Geibel, M., Dehmer, K. J., and Forsline, P. L. 2000. Biological diversity in Malus sieversii. populations from Central Asia. Acta Hortic. 538:43-50.

Janick, J. 1996. Apples. Pages 1-78 in: Fruit Breeding, Tree and Tropical Fruits. Vol. 1. J. Janick and J. N. Moore, eds. John Wiley \& Sons, Hoboken, NJ.

Janisiewicz, W. J., Saftner, R. A., Conway, W. S., and Forsline, P. L. 2008. Preliminary evaluation of apple germplasm from Kazakhstan for resistance to postharvest blue mold in fruit caused by Penicillium expansum. HortScience 43:420-426.

Jurick, W. M., Janisiewicz, W. J., Saftner, R. A., Vico, I., Gaskins, V. L., Park, E., Forsline, P. L., Fazio, G., and Conway, W. S. 2011. Identification of wild apple germplasm (Malus spp.) accessions with resistance to the postharvest decay pathogens Penicillium expansum and Colletotrichum acutatum. Plant Breed. 130:481-486.

Khan, M. A., Durel, C., Duffy, B., Drouet, D., Kellerhals, M., Gessler, C., and Patocchi, A. 2007. Development of molecular markers linked to the 'Fiesta' linkage group 7 major QTL for fire blight resistance and their application for marker-assisted selection. Genome 50:568-577. 
Khan, M. A., Zhao, Y. F., and Korban, S. S. 2012. Molecular mechanisms of pathogenesis and resistance to the bacterial pathogen Erwinia amylovora, causal agent of fire blight disease in Rosaceae. Plant Mol. Biol. Report. 30:247-260.

Khanizadeh, S., Groleau, Y., Granger, R., Cousineau, J., and Rousselle, G. L. 2000. New hardy rootstocks from the Quebec apple breeding program. Acta Hortic. 538:719-721.

Lauri, P. É., and Laurens, F. R. 2005. Architectural types in apple (Malus X domestica Borkh.). Crops: growth, quality and biotechnology. Pages 1300-3013 in: Crops: Growth, Quality and Biotechnology. R. Dris, ed. WFL Publishing, Helsinki, Finland.

Le Roux, P. M., Flachowsky, H., Hanke, M., Gessler, C., and Patocchi, A. 2012. Use of a transgenic early flowering approach in apple (Malus $\times$ domestica Borkh.) to introgress fire blight resistance from cultivar Evereste. Mol. Breed. 30:857-874.

Le Roux, P. M., Flachowsky, H., Jänsch, M., Kellerhals, M., Patocchi, A., and Fanke, M.-V. 2014. Development of apple pre-breeding genotypes highly resistant to fire blight by early flowering. Acta Hortic. 1048:55-64.

Le Roux, P. M., Khan, M. A., Broggini, G. A. L., Duffy, B., Gessler, C. and Patoochi, A. 2010. Mapping of quantitative trait loci for fire blight resistance in the apple cultivars 'Florina' and 'Nova Easygro'. Genome 53:710-722.

Luby, J. 2003. Taxonomic classification and brief history. Pages 1-14 in: Apples: Botany, Production and Uses. D. C. Ferree and I. J. Warrington, eds. CABI Publishing, Cambridge, MA.

Luby, J., Alspach, P. A., Bus, V. G. M., and Oraguzie, N. C. 2002. Field Resistance to fire blight in a diverse apple (Malus sp.) germplasm collection. J. Am. Soc. Hortic. Sci. 127:245-253.

Luby, J., Forsline, P., Aldwinckle, H., Bus, V., and Geibel, M. 2000. Silk road apples-collection, evaluation, and utilization of Malus sieversii from Central Asia. HortScience 36:225-231.

McManus, P. S., and Jones, A. L. 1994. Epidemiology and genetic analysis of streptomycin resistant Erwinia amylovora from Michigan and evaluation of oxytetracycline for control. Phytopathology 84:627-633.

McManus, P. S., Stockwell, B. O., Sundin, G. W., and Jones, A. L. 2002. Antibiotic use in plant agriculture. Annu. Rev. Phytopathol. 40:443-465.

Momol, M. T., Aldwinckle, H. S., Forsline, P. L., and Lamboy, W. F. 1999. Fire blight resistance and horticultural evaluation of wild Malus populations from Central Asia. Acta Hortic. 489:229-234.

Norelli, J. L., Aldwinckle, H. S., and Beer, S. V. 1988. Virulence of Erwinia amylovora strains to Malus sp. Novole plants grown in vitro and in the greenhouse. Phytopathology 78:1292-1297.

Norelli, J. L., Holleran, H. T., Johnson, W. C., Robinson, T. L., and Aldwinckle, H. S. 2003a. Resistance of Geneva and other apple rootstocks to Erwinia amylovora. Plant Dis. 87:26-32.
Norelli, J. L., Jones, A. L., and Aldwinckle, H. S. 2003b. Fire blight management in the twenty-first century. Plant Dis. 87:756-765.

Nybom, H., Mikiciński, A., Garkava-Gustavsson, L., Sehic, J., Lewandowski, M. and Sobiczewski, P. 2012. Assessment of fire blight tolerance in apple based on plant inoculations with Erwinia amylovora and DNA markers. Trees (Berl.) 26 199-213.

Peil, A., Flachowsky, H., Hanke, M. V., Richter, K., and Rode, J. 2011. Inoculation of Malus $\times$ robusta 5 progeny with a strain breaking resistance to fire blight reveals a minor QTL on LG5. Acta Hortic. 896:357-362.

Richards, C. M., Volk, G. M., Reeves, P. A., Reilley, A. A., Henk, A. D., Forsline, P. L., and Aldwinckle, H. S. 2009a. Selection of stratified core sets representing wild apple (Malus sieversii). J. Am. Soc. Hortic. Sci. 134:228-235.

Richards, C. M., Volk, G. M., Reilley, A., Henk, A. D., Lockwook, D. R., Reeves, P. A., and Forsline, P. L. 2009b. Genetic diversity and population structure in Malus sieversii, a wild progenitor species of domesticated apple. Tree Genet. Genomes 5:339-347.

Russo, N. L., Burr, T. J., Breth, D. I., and Aldwinckle, H. S. 2008. Isolation of Streptomycin-resistant isolates of Erwinia amylovora in New York. Plant Dis. 92:714-718.

Sobiczewski, P., Peil, A., Mikiciński, A., Richter, K., Lewandowski, M. Żurawicz, E., and Kellerhals, M. 2015. Susceptibility of apple genotypes from European genetic resources to fire blight (Erwinia amylovora). Eur. J. Plant Pathol. 141:51-62.

Stockwell, V. O., Johnson, K. B., and Loper, J. E. 1998. Establishment of bacterial antagonists of Erwinia amylovora on pear and apple blossoms as influenced by inoculum preparation. Phytopathology 88:506-513.

USDA, ARS, National Plant Germplasm System (NPGS). 2008. Germplasm Resources Information Network (GRIN). National Germplasm Resources Laboratory, Beltsville, MD. Retrieved 21 October 2015 from https://www.ars-grin.gov/npgs/

USDA, National Organic Program (NOP). 2015. Sunset 2015 Amendments to the National List. Agricultural Marketing Service. 80:146. Online Publication http://www.regulations.gov/\#!documentDetail;D=AMS-NOP-15-0015-0001.

van der Zwet, T., Orolaza-Halbrendt, N., and Zeller, W. 2012. Fire Blight: History, Biology, and Management. APS Press, St. Paul, MN.

Volk, G. M., Chao, C. T., Norelli, J., Brown, S. K., Fazio, G., Peace, C., McFerson, J., Zhong, G.-Y., and Bretting, P. 2015. The vulnerability of US apple (Malus) genetic resources. Genet. Resour. Crop Evol. 62:765-794.

Volk, G. M., Richards, C. M., Reilley, A. A., Henk, A. D., Reeves, P. A., Forsline, P. L., and Aldwinckle, H. S. 2008. Genetic diversity and disease resistance of wild Malus orientalis from Turkey and southern Russia. J. Am. Soc. Hortic. Sci. 133:383-389. 